\title{
The growth response of coffee (Coffea arabica $L$ ) plants to organic manure, inorganic fertilizers and integrated soil fertility management under different irrigation water supply levels
}

\author{
Abel Chemura
}

Received: 3 December 2013/Accepted: 5 April 2014/Published online: 8 May 2014

(c) The Author(s) 2014. This article is published with open access at Springerlink.com

\begin{abstract}
A study was carried out to determine the effects of organic, inorganic fertilizers and integrated soil fertility management and irrigation levels $(1,000,750$ and $500 \mathrm{ml}$ per planting station) on coffee growth. There were no significant differences $(p>0.05)$ in girth, number of leaves and number of primaries due to the different soil fertility management options. Significant differences $(p<0.05)$ due to soil nutrient sources were observed in coffee height where inorganic fertilizer treatment resulted in tallest coffee plants $(47.4 \mathrm{~cm})$ and integrated soil fertility having the shortest coffee trees $(42.8 \mathrm{~cm})$ after 1 year. The highest irrigation level of $1,000 \mathrm{ml}$ had the tallest plants with thickest stems while the lowest level had the shortest and thinnest plants $(p<0.05)$. No significant differences were observed in the number of leaves and number of primaries due to irrigation treatments. Results indicate that inorganic fertilizers are the most effective at high irrigation levels while organic manure performs better than inorganic fertilizers under low irrigation water levels.
\end{abstract}

Keywords Organic manure $\cdot$ Coffee growth $\cdot$ Integrated fertility $\cdot$ Irrigation $\cdot$ Drought

\section{Introduction}

Soil fertility management and water supply are important for successful crop production in all agricultural commodities. The use of inorganic fertilizers has been a

\section{A. Chemura ( $\square)$}

Department of Environmental Science and Technology, Chinhoyi University of Technology, P.Bag 7724, Chinhoyi, Zimbabwe

e-mail: achemura@gmail.com significant contributor to increased crop productivity since the green revolution, and has resulted in reduced use of organic nutrient sources that farmers have relied on for centuries (Satyanarayana et al. 2002). The quality of fertilizers, their costs and yield contribution are as variable as their sources. The most common sources of organic manure used in crop production are livestock dung, composted and green crop residues, farmyard matter and organic manure from natural systems and material production systems (Lekasi et al. 2001; Mufwanzala and Dikinya 2010; Satyanarayana et al. 2002). The need for renewable, locally available and cheaper options for supplying nutrient to crops is increasingly becoming important because of the need for sustainable agriculture (Ahmad et al. 2006; Baker et al. 2001; Nyalemegbe et al. 2009; Zafar et al. 2011). With growing demands for sustainably produced agricultural produce for environmental, social and food safety reasons, the use and recycling of organic matter is becoming inevitable, particularly for the export market, which depended on commodities such as coffee.

Sustainable agriculture is a production process and farm management system that has positive economic, ecological and social benefits in the short and long term (Kilian et al. 2006). The levels of sustainability vary on a sliding scale from the strict organic farming methods that demand perfect quality of the production process and the environment to general guidelines and codes of conduct on various aspects of the expectations of the production system (Kilian et al. 2006; Ponte 2004). Use of organic soil fertility options is among the key attributes of sustainable agriculture. Maintaining physical, chemical and biological soil properties for plant growth and environmental efficiency requires the input of organic matter that is decomposed into nutrients and used up by plants. Sustainable production is becoming a necessity for coffee sectors to remain 
competitive in the global trade against oversupply and price fluctuations that in some years result in coffee price crisis.

Reliance on inorganic fertilizers may not be sustainable in the long term given that soils may lose microorganisms and become acidic, having unstable aggregates leading to erosion and general degradation, and this may explain yield decline with time despite the consistent use of inorganic fertilizers (Nyalemegbe et al. 2009). Despite this, access to fertilizers especially by smallholder farmers is affected by many factors, some of which are artificial (Ebong and Ebong 2006). Cattle manure has potential to be used as an organic nutrient source in coffee production (Chemura et al. 2010a; Lekasi et al. 2001; Njoroge et al. 1990) while recycling coffee wastes such as pulp and prunings as direct inputs or in combination with green manures and live mulch in nutrient management were effective in promoting coffee growth and yield and also economically viable (Chemura et al. 2010b).

On the other hand, some studies have shown that organic manures are very important for maintaining soil organic matter and supplying nutrients to the coffee systems, but may not be enough for balanced plant nutrient flows and for achieving profitable yield levels (Stockdale et al. 2002). This is because the maximum $\mathrm{N}$ obtainable from common organic manures is $<10 \%, \mathrm{P}<2 \%$ and $\mathrm{K}$ $<10 \%$ of dry matter compared with high nutrient outflows of up to $105 \mathrm{~kg} \mathrm{ha}^{-1}$ of $\mathrm{N}, 13 \mathrm{~kg} \mathrm{ha}^{-1}$ of $\mathrm{P}$ and $107 \mathrm{~kg} \mathrm{ha}^{-1}$ of $\mathrm{K}$ to achieve yield levels of $1 \mathrm{t} \mathrm{ha}^{-1}$ per year resulting in serious negative nutrient balances (Van der Vossen 2005; Wrigley 1988). Given that the negative nutrient balance from use of organic manures is only apparent in yielding coffee, it may be that organic manures, or at least integrated, are able to provide a positive nutrient balance when the coffee has not reached bearing age. Some studies have shown that integrating organic and inorganic fertilizers is competitive in terms of growth and economic returns for crops (Ahmad et al. 2006; Nyalemegbe and Oteng 2009; Reganold et al. 2001) and other cultures (Afzal et al. 2007).

Water supply is increasingly becoming important in coffee production given the unreliable rainfalls and frequent droughts that affect growth, yield and quality of coffee (DaMatta 2004; Worku and Astatkie 2010). According to Coffee Management Services (2007), irrigation is an expensive management practice because it involves pumping costs, labor and other equipment requirements. This is despite the fact that soil water is important for keeping plant nutrients in solution, maintaining soil microorganisms, and for root and shoot development and functioning, all of which have a bearing on production levels and quality (Stockdale et al. 2002). Studies on irrigation levels and $\mathrm{N}$ rates of pomegranate and coffee showed that the high rates of $\mathrm{N}$ are effective when there is minimum water depletion (Ibrahim and El-Samad 2009; Kutywayo et al. 2010). This indicates that with limited water supply such as in cases of drought, $\mathrm{N}$ and probably other nutrients are not easily available from inorganic sources of soil nutrients.

Soil organic matter plays an important role in moisture retention and therefore the use of organic manures is considered as a climate change adaptation strategy. Soil moisture is important in the decomposition of organic matter and making nutrients from both organic and inorganic fertilizers available to the plant (El-Kader et al. 2010). Irrigation water management is very critical in coffee production. Excessive irrigation is costly and moisture stress results in dieback, wilting and opportunistic disease and pest attacks, resulting in reduced production in both cases. Depending on the timing, moisture stress can also result in floral abortion, which results in reduced yields. The interaction between sources of nutrients and irrigation levels is therefore very important, especially in the context of reducing production costs and adapting to climate change in the coffee sector. Soil fertility management and irrigation water supply are therefore two important management functions in coffee production.

The objectives of this study were to establish the growth effects of different soil fertility management options and irrigation levels on coffee vegetative growth, which has direct implications on coffee yield and quality. In addition, the synergistic effects of soil fertility management and irrigation levels were also investigated to identify if organic soil fertility management can sustain coffee growth when water supply is low by improving soil moisture conservation and water use efficiency. This information is important in building a productive, sustainable and robust coffee production system under challenges of environmental accounting and reduced rainfalls in rain-fed systems due to climate change.

\section{Materials and methods}

Study sites and treatments

The experiment was carried out at the Coffee Research Institute, Chipinge, Zimbabwe $\left(32^{\circ} 39 / \mathrm{W}, 20^{\circ} 13 / \mathrm{S}\right.$ and altitude $1,100 \mathrm{~m}$ above sea level). The climate in Chipinge is subtropical with two distinct seasons: the dry season and the wet season. Average total annual rainfall is $1,180 \mathrm{~mm}$ of which $80 \%$ fall in 5 months from November to March. The mean maximum temperature is $20^{\circ} \mathrm{C}$ and minimum is $14{ }^{\circ} \mathrm{C}$. Healthy coffee seedlings (variety Catimor 129) that were 6 months old were transplanted into 51 earthen pots. 
Table 1 Chemical properties of the soil and composted humus

\begin{tabular}{lcc}
\hline Nutrients & Soil & Composted humus \\
\hline $\mathrm{pH}$ & 6.4 & 6.7 \\
$\mathrm{Ec}_{\mathrm{e}}(\mathrm{dS} / \mathrm{m})$ & 0.94 & 0.91 \\
$\mathrm{~N}(\%)$ & 0.89 & 1.13 \\
$\mathrm{P}(\%)$ & 0.33 & 0.54 \\
$\mathrm{~K}(\%)$ & 0.31 & 0.39 \\
$\mathrm{C}(\%)$ & 14.2 & 28.3 \\
Moisture $(\%)$ & 45 & 53 \\
\hline
\end{tabular}

The seedlings were stripped of their initial soil and then planted in media that contained the different soil fertility treatments. The treatments consisted of organic, integrated and inorganic fertility management options.

The organic manure treatment contained composted humus obtained from under a forest after clearing fresh litter and composted by putting it in a composting pit for 4 weeks. Sieved $3 \mathrm{~kg}$ of composted humus was mixed thoroughly with $2 \mathrm{~kg}$ of soil media. For integrated fertility option, $1 \frac{1}{2} \mathrm{~kg}$ of composted humus was mixed with soil and $25 \mathrm{~g}$ of inorganic fertilizer. The inorganic fertilizer treatment (control) had $50 \mathrm{~g}$ of inorganic fertilizer mixed with soil before planting coffee seedlings in the soil media. The media mixed with the fertility treatments were topsoil obtained from an old fallow. The soils used are orthoferallitic according to the Zimbabwe Classification System, derived from Umkondo Quartzites and shales and consist of deep, fine-to-medium grained sandy loams on the surface (Thomson and Purves 1981). The chemical properties of the soil and the composted humus used are shown in Table 1.

\section{Trial set up}

The fertilizer application rates for the inorganic and integrated fertility management treatment were calculated from the published rates of inorganic fertilizer recommendations for young coffee in the field which are $1 \mathrm{t} \mathrm{ha}^{-1}$ per year (Logan and Biscoe 1987). At a plant spacing of $3 \mathrm{~m} \times 1.5$, a plant population of 4,450 plants $\mathrm{ha}^{-1}$ will be obtained using double covas and therefore half the rate per plant will give $50 \mathrm{~g}$ per planting station. All soil fertility treatment applications were repeated after 6 months. Three water levels were used as irrigation treatments. These were a high rate with $1,000 \mathrm{ml}$, a normal rate with $750 \mathrm{ml}$ (Control) and low rate with $500 \mathrm{ml}$. All the water treatments were applied bi-weekly.

Measurements and data analysis

Measurements were taken on a bi-weekly interval on counts of the number of leaves (recorded for the first
6 months), girth measured at $5 \mathrm{~cm}$ from the surface using a vernier calipers height measured to apex leaf using a meter rule and counts of number of primaries for 1 year. Counts of number of leaves and number of primaries were log transformed before statistical analysis. Repeated measurements analysis of variance was used to determine the significance of the variance between treatments on the data recorded over time (mean) and analysis of variance was used for analysis of final recording of data (Final) in Genstat 14 software (VSNI, 2011) and linear regression and analysis of covariance were done in Excel and R.

\section{Results}

Effects of soil fertility on coffee growth

Effect of fertility option on coffee biometric characteristics

Inorganic fertilizer produced the tallest coffee seedlings $(p<0.05)$ with a final height of $124.8 \mathrm{~cm}$. Combining inorganic and organic fertilizers performed better than just organic fertilizers alone in both the mean height and the final height of the coffee seedlings. Organic manure resulted in the shortest coffee plants with a mean height of $42.8 \mathrm{~cm}$ and a final height of $78.6 \mathrm{~cm}$ (Fig. 1). Mean and final coffee stem thickness did not significantly respond $(p>0.05)$ to soil fertility treatments (Fig. 2). There were no significant differences $(p>0.05)$ due to soil fertility treatments in mean and final number of leaves and number of primaries (Table 2).

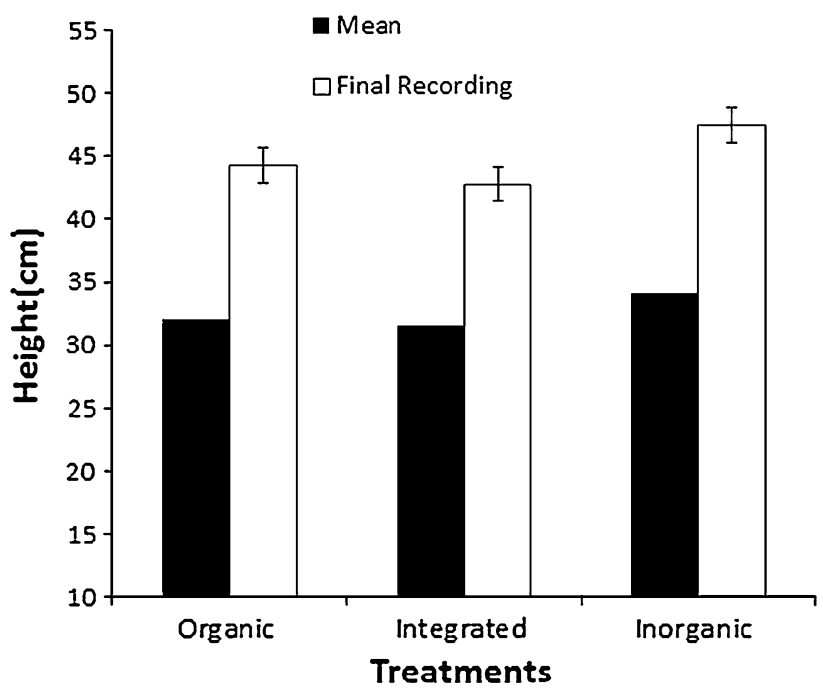

Fig. 1 Effect of soil fertility management options on coffee height 


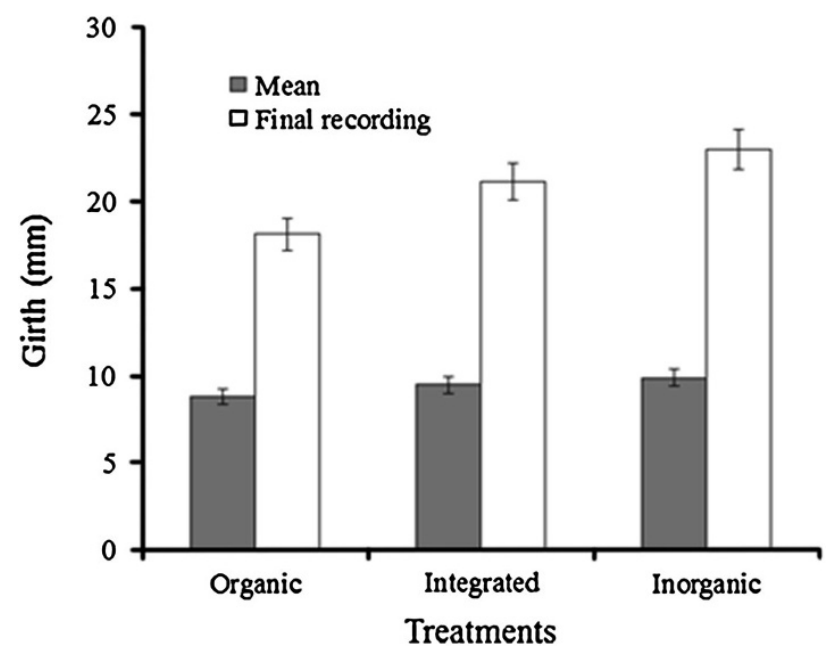

Fig. 2 Effect of soil fertility management options on coffee girth

Table 2 Effects of treatment on number of leaves and branches

\begin{tabular}{lccllc}
\hline Treatment & \multicolumn{2}{l}{ Number of leaves } & & \multicolumn{2}{l}{ Number of primaries } \\
\cline { 2 - 3 } & Mean & Final & & Mean & Final \\
\hline Inorganic & 14.9 & 19.8 & & 8.4 & 17.1 \\
Integrated & 14.3 & 18.7 & & 8.7 & 18.2 \\
Organic & 15.5 & 20.8 & & 8.9 & 17.7 \\
$p$ & 0.364 & 0.282 & & 0.082 & 0.115 \\
\hline
\end{tabular}

Table 3 Growth partitioning between plant parts due to soil fertility treatments

\begin{tabular}{llll}
\hline Treatment & Factors & $r^{2}$ & $p$ \\
\hline Organic & Primaries and height & 0.52 & $0.0293^{*}$ \\
& Girth and primaries & 0.37 & 0.0848 \\
& Height and girth & 0.77 & $0.0018^{* *}$ \\
Integrated & Primaries and height & 0.058 & 0.5327 \\
& Girth and primaries & 0.46 & $0.0453^{*}$ \\
& Height and girth & 0.004 & 0.8677 \\
Inorganic & Primaries and height & 0.23 & 0.1913 \\
& Girth and primaries & 0.16 & 0.2801 \\
& Height and girth & 0.18 & 0.2589 \\
\hline
\end{tabular}

* Significant $(p<0.05)$

** Highly significant $(p<0.01)$

\section{Effects of soil fertility options on the growth partitioning}

There was evidence in proportional growth of girth, number of primaries and height when coffee plants are under organic manure $(p<0.05$, Table 3 ; Fig. $3 \mathrm{a}, \mathrm{b}, \mathrm{c})$. This partitioning was not apparent under inorganic fertilizers as none of the relationships was neither strong nor significant.
The strongest proportional growth was between height and girth under organic manure $\left(r^{2}=0.77, p<0.05\right)$. Under integrated soil fertility management, the relationship between girth and number of primaries was significant $\left(r^{2}=0.46, p<0.05\right.$, Fig. 3d, e, f). Examination of the relationships indicated that under inorganic fertilizers, there is more growth of primaries at the expense of girth and height, and more height at the expense of girth (Fig. $3 \mathrm{~g}$, h).

\section{Effects of soil fertility options on the growth patterns}

Coffee plant girth, number of leaves, height and number of primaries showed a very strong $\left(r^{2}>0.9\right)$ linear growth over time (Table 4). Analysis of covariance showed that there were no significant differences between the slopes of girth, number of leaves and number of primaries $(p>0.05)$ between organic, integrated and inorganic fertilizer options over time.

Effect of water levels on coffee growth

\section{Effect of water levels on biometric characteristics}

The young coffee plants significantly responded $(p<0.05)$ to irrigation water amounts in terms of height and girth. Coffee plants were tallest $(118.6 \mathrm{~cm})$ and had thickest plant stems $(10.2 \mathrm{~mm})$ when supplied the more irrigation water levels and shortest $(89.9 \mathrm{~cm})$ and thinnest $(8.8 \mathrm{~mm})$ under the lowest irrigation amounts (Fig. 4a, b). In terms of number of leaves and number of primaries, there were no significant differences $(p>0.05)$ due to different irrigation levels (Fig. 4c, d). The coffee plants developed comparable numbers of primaries under lower and intermediate irrigation levels and these were lower than the number that developed under the highest irrigation level (Fig. 4c). The highest irrigation level had the highest number of leaves while more leaves developed under lowest irrigation rate than under the intermediate levels.

\section{Effect of water levels on growth partitioning}

There was no significant partitioning in the growth of girth, number of primaries and height when coffee plants are irrigated with high, medium and low amounts $(p>0.05$, Table 4). Growth partitioning was only significantly proportional between girth and number of primaries when coffee plants were provided with medium levels of irrigation $\left(r^{2}=0.45, p<0.05\right.$, Table 5).

\section{Interaction between soil fertility options and water levels}

The interaction between nutrient source and irrigation water level was only significant $(p<0.05)$ in coffee 


\section{Organic manure}
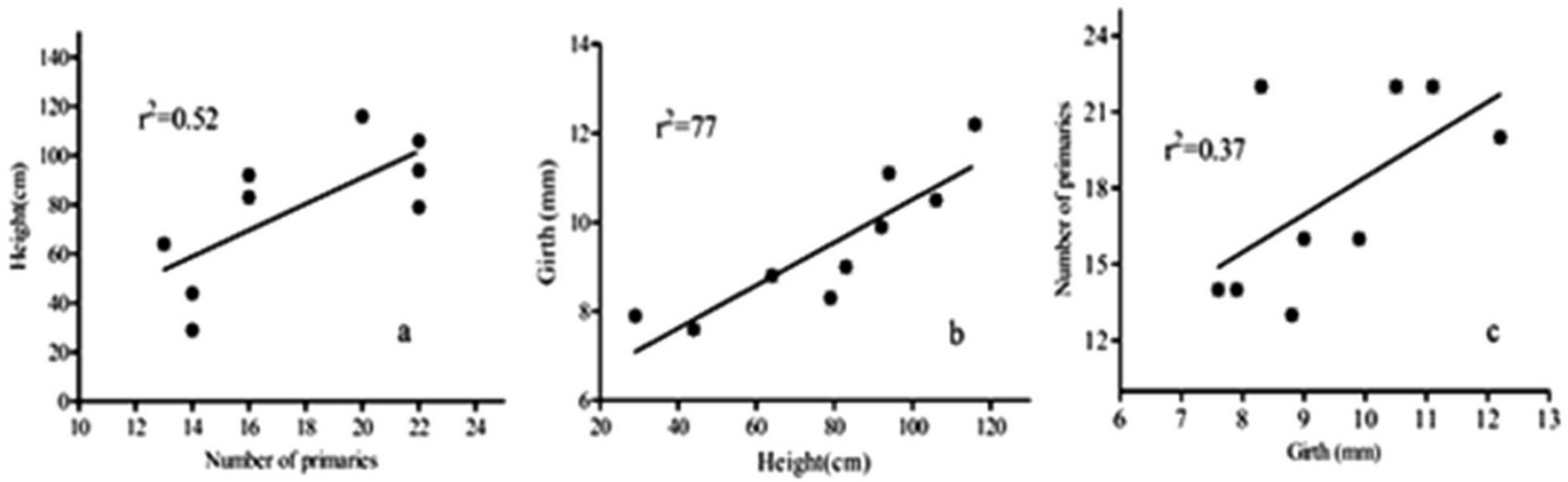

\section{Integrated fertility}
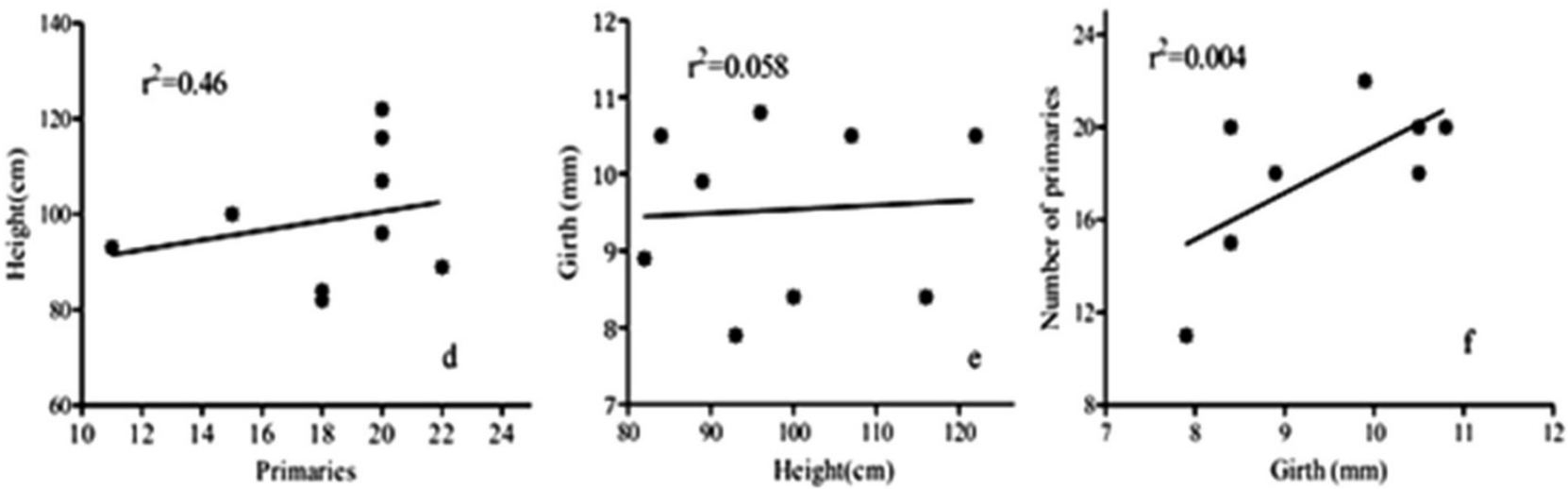

Inorganic fertilizer
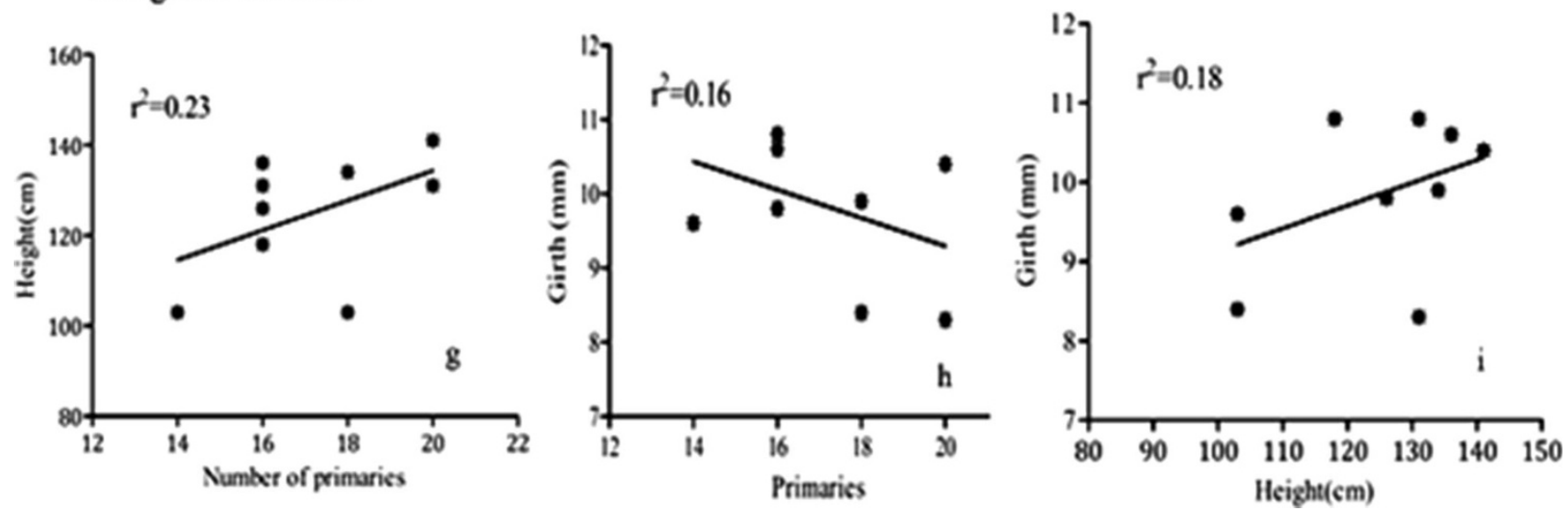

Fig. 3 Coffee growth partitioning between number of primaries, height and girth under different fertility options

height where the highest irrigation rate $(1,000 \mathrm{ml})$ under inorganic fertilizer had the tallest coffee plants. The results indicate that coffee plants grow better under inorganic fertilizers when there is more irrigation water supply as shown by height, girth and number of primaries (Figs. 5, 6, 7). However, more growth is achieved under low irrigation level when organic manure is used for soil fertility management (Figs. 5, 6, 7). Taller plants and thicker stems of coffee plants were realized under organic manure while integrated fertility had more primaries and leaves than the inorganic and organic treatments. 
Table 4 Growth functions for each of the treatments for girth, leaves, primaries and height

\begin{tabular}{lllll}
\hline Attribute & Treatment & $r^{2}$ & $p$ & Function \\
\hline Girth & Organic & 0.98 & $<0.001$ & $y=0.15 x+2.4$ \\
& Integrated & 0.98 & $<0.001$ & $y=0.15 x+2.5$ \\
& Inorganic & 0.99 & $<0.001$ & $y=0.16 x+2.5$ \\
Height & Organic & 0.96 & $<0.001$ & $y=0.79 x+13.1$ \\
& Integrated & 0.95 & $<0.001$ & $y=0.68 x+15.2$ \\
& Inorganic & 0.94 & $<0.001$ & $y=0.85 x+13.8$ \\
Leaves & Organic & 0.97 & $<0.001$ & $y=0.45 x+8.1$ \\
& Integrated & 0.96 & $<0.001$ & $y=0.46 x+7.4$ \\
& Inorganic & 0.97 & $<0.001$ & $y=0.51 x+7.9$ \\
Primaries & Organic & 0.98 & $<0.001$ & $y=0.23 x-1.7$ \\
& Integrated & 0.96 & $<0.001$ & $y=0.23 x-1.4$ \\
& Inorganic & 0.93 & $<0.001$ & $y=0.24 x-1.6$ \\
\hline
\end{tabular}
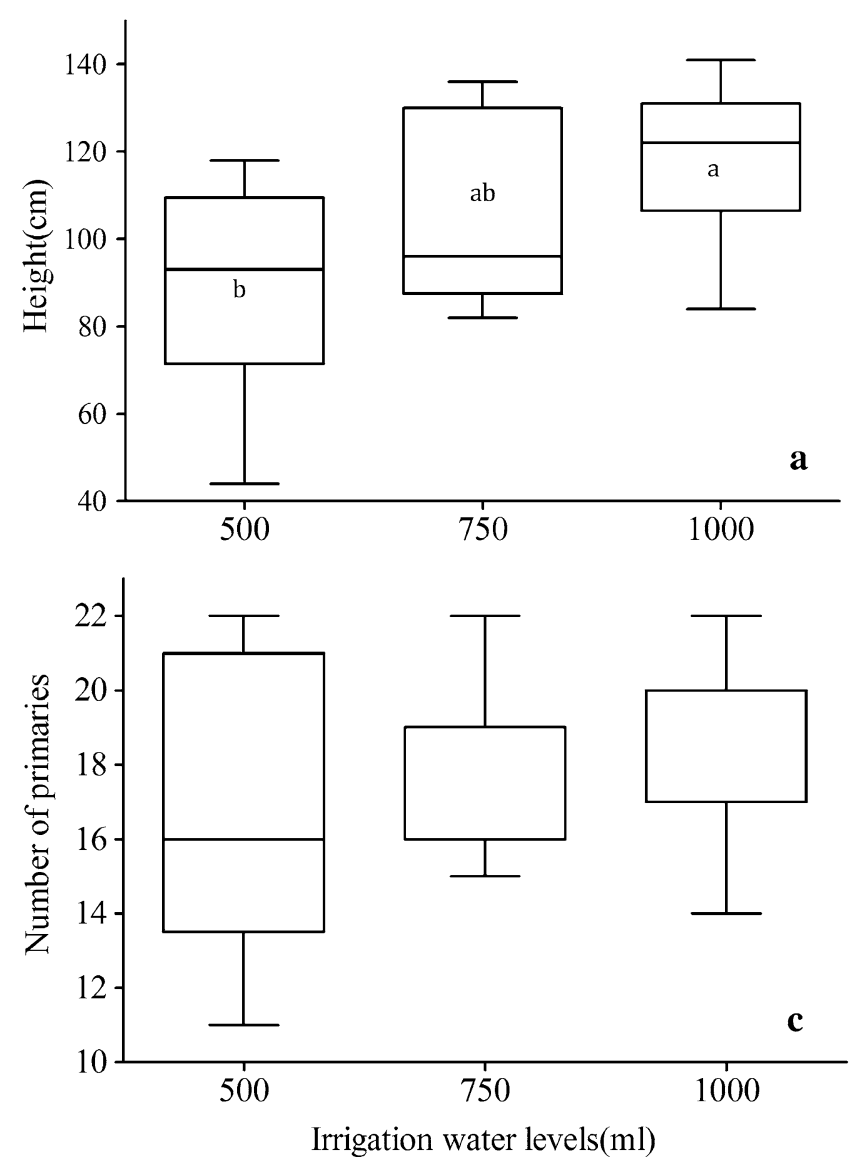

Fig. 4 Growth response of young coffee to different irrigation levels. a shows the mean height, $\mathbf{b}$ shows the mean girth, $\mathbf{c}$ shows the mean number of primaries, and $\mathbf{d}$ shows the mean number of leaves per
Table 5 Growth partitioning due to irrigation water levels

\begin{tabular}{llll}
\hline Treatment $(\mathrm{ml})$ & Factors & $r^{2}$ & $p$ \\
\hline 1,000 & Primaries and height & 0.057 & 0.5347 \\
& Girth and primaries & 0.034 & 0.6356 \\
750 & Height and girth & 0.285 & 0.1391 \\
& Primaries and height & 0.044 & 0.5891 \\
& Girth and primaries & 0.449 & $0.0484 *$ \\
500 & Height and girth & 0.095 & 0.4194 \\
& Primaries and height & 0.036 & 0.6082 \\
& Girth and primaries & 0.187 & 0.2448 \\
& Height and girth & 0.099 & 0.4086 \\
\hline
\end{tabular}

* Significant $(p<0.05)$

\section{Discussion}

The readily available $\mathrm{N}$ from the inorganic fertilizer was fundamental in producing taller coffee plants than the
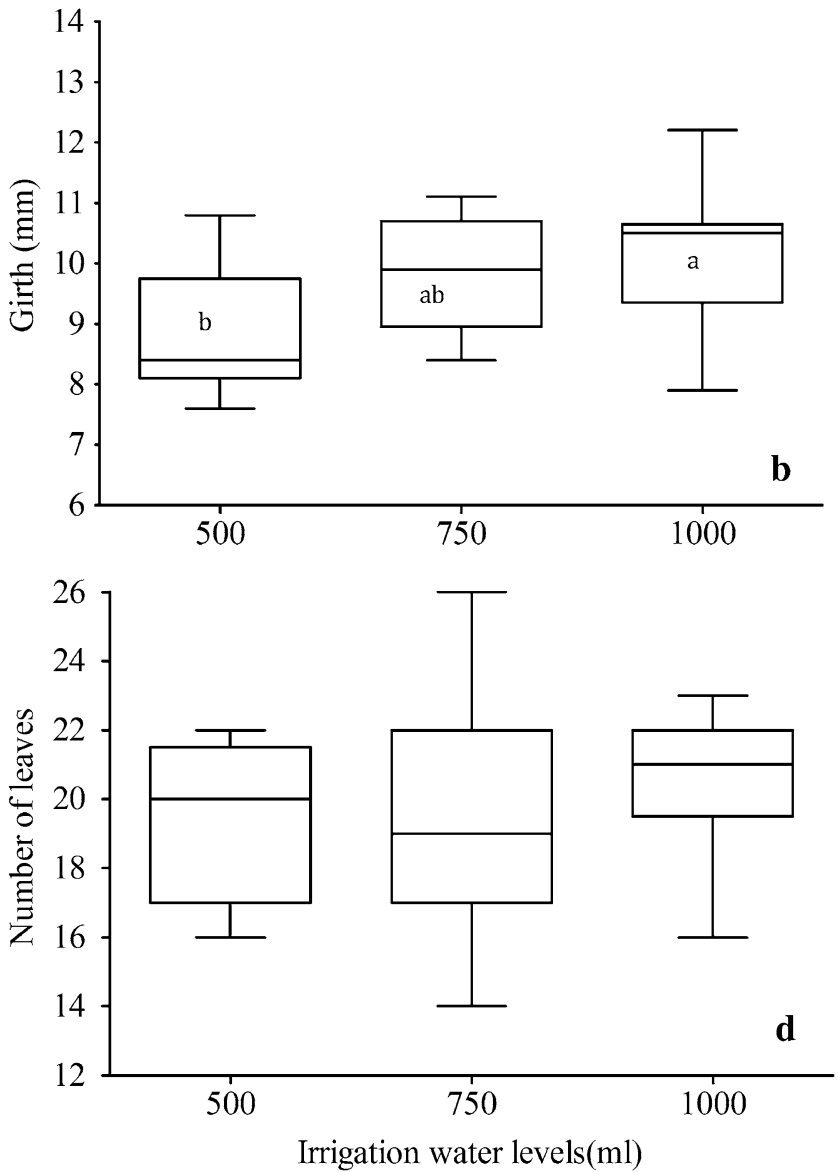

treatment [treatments with different letters significantly different after Tukey test $(p<0.05)]$ 


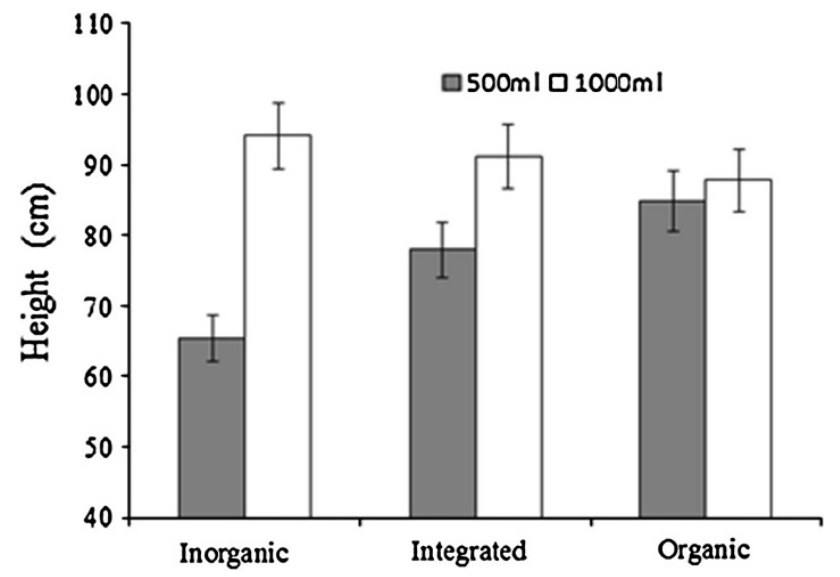

Fig. 5 Coffee plant height under low and high water levels

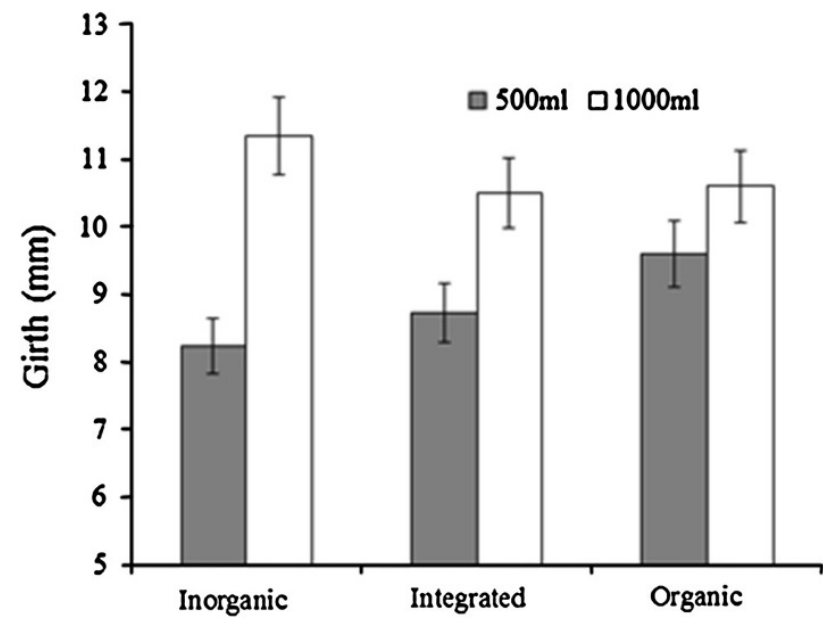

Fig. 6 Coffee girth under low and high water supply levels

organic manure which needs time to decompose and produce the required nutrients. Thus, the differences between organic manure and inorganic fertilizers in height may be because of the lag required for organic manure to benefit crop plants, unlike inorganic fertilizers. The height benefits could not be translated into benefits on girth, as stem thickness, unlike apical growth, is promoted by availability of $\mathrm{P}$ which tends to be more abundant in organic nutrient sources, making the organic treatment and the integrated fertility option as competitive as inorganic fertilizers (Ahmad et al. 2006; Ibrahim and El-Samad 2009; Mufwanzala and Dikinya 2010).

Using organic manure and integrating it with inorganic fertilizer managed to produce a growth pattern (as measured through leaf and primary development) that is comparable to that of recommended levels of inorganic fertilizers. The competitive performance of integrated fertilizer to inorganic fertilizers was also reported by
Nyalemegbe (2009) who concluded that combining poultry manure with inorganic fertilizers resulted in similar yields in rice as those obtained from using inorganic fertilizers alone. In addition, composted humus could add to other sources of organic soil nutrients that could be combined with inorganic fertilizers such as composted coffee pulp, cattle manure, poultry manure, sugarcane filter cake and crop residues (Chemura et al. 2010b; Van der Vossen 2005). Humus has the added advantage that it can be locally available from forest patches and this underlines the importance of managing trees on or around coffee farms for nutrient cycling and humus input (Haggar et al. 2011; Stockdale et al. 2002; Tscharntke et al. 2011). This becomes even more important given the problems of smallholder farmers assessing chemical fertilizers (Ebong and Ebong 2006; Lekasi et al. 2001).

Although the results showed that coffee grows more when applied with inorganic fertilizers, the growth partitioning showed that there is no balanced growth under this fertilizer regime. Organic manures had the most significant proportional growth indicating that the organic sources of nutrients are able to provide a balanced supply of nutrients. This is unlike inorganic fertilizers that supply only the nutrients in their formulation which may favor growth of some specific parts of the plant (Lekasi et al. 2001). For example, while the $\mathrm{N}$ may support growth of new leaves and height, $\mathrm{P}$, which is the least of the proportion in the fertilizers used in this study, will be important for the development of the woody parts of the plants (Stockdale et al. 2002; Zafar et al. 2011). The balanced developments of both vegetative and woody parts of the plant as provided by organic manure are very important for plants such as coffee whose vegetative parts such as leaves are not harvested. It was surprising that there was no significant growth partitioning due to different levels of irrigation. It is expected that under water stress, the coffee plants will prioritize growth and maintenance of roots and other woody parts of the plant at the expense of vegetative growth of leaves and height (DaMatta 2004; Worku and Astatkie 2010).

The less pronounced growth after the 26th week signifies the response of the coffee plant to abiotic factors particularly temperature during the winter months. The 26th week coincides with the start of winter in the study area and this indicates that although coffee is a perennial plant, plant growth is more pronounced and accelerated in the warm summer months than in cold winters. The coffee plant may also be changing priorities for nutrient allocation from primary growth to fruiting in winter, resulting in reduced vegetative growth. Logan and Biscoe (1987) reported that the coffee plant continually makes new growth the whole year round but it is important to note that the vigor is reduced during winter months as indicated by 


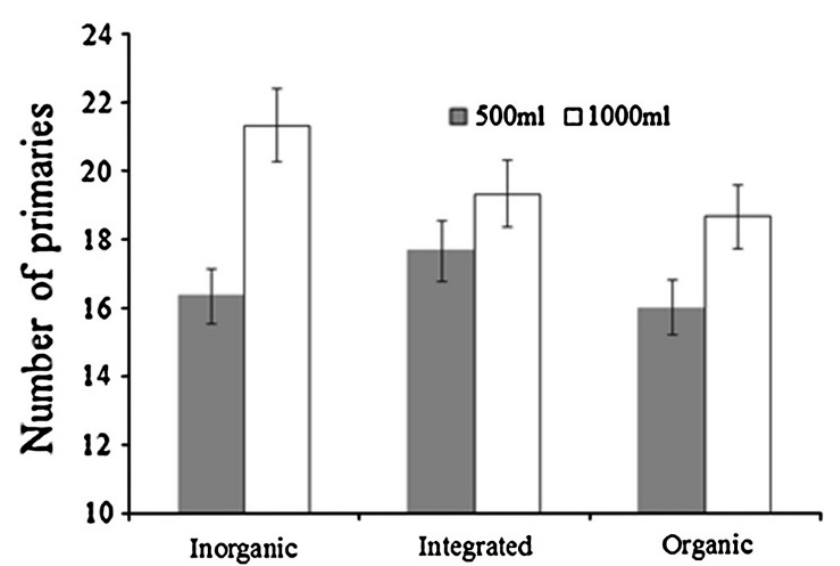

Fig. 7 Number of primaries under low and high water supply levels

the results. This reduced growth is apparent even in the absence of both soil fertility and water deficit and thus, it is important to make sure that the coffee plant has adequate water and soil nutrients to avoid premature leaf senescence, dieback and other effects of water and nutrient shortages at the time when they are most required for supporting fruit development.

The coffee plant responds to increasing the amount of irrigation as indicated by the responses in girth and height. However, in terms of number of primaries and number of leaves, there were no significant responses to increasing water levels and this could be attributed to the fact that the coffee plant has inherent drought tolerance habits that enable it to survive and develop under low water levels. This is explained by Hess et al. (1998) who observed that stoma of coffee are very sensitive to light and in sun-coffee systems, they close even in the abundance of water.

Since the highest water supply level had the tallest and thickest stems, it shows that the young coffee plants significantly responds to increased irrigation. This reinforces the suggestion by Logan and Biscoe (1987) that in coffee production, irrigation can be the deciding factor on success. It is however not clear from this study how the different water levels applied are related to crop requirements and actual water use efficiency. The water use of crops increases under increased water supply inasmuch as water loss through transpiration also increases (Ibrahim and El-Samad 2009).

The positive interaction between irrigation levels and organic sources on height and the improved growth performance of coffee plants under low water supply levels point to the importance of organic manure in regulating soil water for plant use. Ibrahim and El-Samad (2009) also reported that water use significantly decreases with increasing amount of organic manure in the soil. The increased efficiency in growth of coffee plants under organic and integrated soil fertility under low irrigation could be due to the positive effects of organic manure on soil physical and chemical properties. It has been established that soil structure, texture, and porosity improve if organic matter is added to the soil which resultantly increases the soil water holding capacity (Lekasi et al. 2001; Stockdale et al. 2002). However, the availability of nutrients such as $\mathrm{P}$ and $\mathrm{K}$ from organic sources is significantly affected by availability of water in the soil and thus sufficient water should always be available for immobilizing nutrients from organic sources (Abed El-Calder et al. 2010; Ibrahim and El-Samad 2009; Zafar et al. 2011).

\section{Conclusion}

The results indicated that organic and integrated nutrient sources are able to provide sufficient nutrients for healthy coffee growth. The use of integrated fertility management could be the most attractive option given that it reduces on both costs of inorganic fertilizers and also on quantities of composts required for efficient coffee growth. Higher levels of irrigation are required for promoting growth in coffee but exact crop water requirements for young coffee need to be established to avoid oversupplying or undersupplying irrigation water. The use of organic manure improves the growth performance of young coffee under low water levels while application of inorganic fertilizers results in more growth at higher water levels. Further studies are required to determine if these trends are carried further to coffee yield and quality.

Open Access This article is distributed under the terms of the Creative Commons Attribution License which permits any use, distribution, and reproduction in any medium, provided the original author(s) and the source are credited.

\section{References}

Abd El-Kader A, Shaaban S, Abd El-Fattah M (2010) Effect of irrigation levels and organic compost on okra plants (Abelmoschus esculentus L.) grown in sandy calcareous soil. Agric Biol J North America 1(3):225-231

Afzal M, Rab A, Akhtar N, Khan MF, Barlas A, Qayyum M (2007) Effect of organic and inorganic fertilizers on the growth performance of bighead carp (Aristichthys nobilis) in polyculture system. Int J Agric Biol 9(6):931-933

Ahmad R, Naseer A, Zahir ZA, Arshad M, Sultan T, Ullah MA (2006) Integrated use of recycled organic waste and chemical fertilizers for improving maize yield. Int $\mathrm{J}$ Agric Biol 8(6):840-843

Baker P, Bentley J, Charveriat C, Dugne H, Leftoy T, Munyua H (2001) The coffee smallholder. In: Baker P (ed) Coffee futures: a source book of some critical issues confronting the coffee industries. CABI-FEDERACAFE-USDA-ICO, Chinchina, p 111

Chemura A, Mahoya C, Kutywayo D, (2010a) Effect of organic nursery media on germination and initial growth of coffee seedlings. Paper presented at the 23rd colloquium of the association for science and information on coffee (ASIC) 
Chemura A, Waheed A, Hamid FS, Kutywayo D, Chingwara V (2010b) Effect of organic \& inorganic fertilizer on growth, yield and economic performance of Coffee. Pakistan J Sci Tech Dev 29(2):11-15

Coffee Management Services (2007) Coffee: sustainable farming handbook, 2nd edn. Coffee Management Services Ltd, Nairobi

DaMatta FM (2004) Exploring drought tolerance in coffee: a physiological approach with some insights on plant breeding. Braz J Plant Phys 16(1):1-6

Ebong VO, Ebong MV (2006) Demand for fertilizer technology by smallholder crop farmers for sustainable agricultural development in Akwa Ibom State, Nigeria. Int J Agric Biol 8(6):728-731

El-Kader A, Shaaban S, El-Fattah M (2010) Effect of irrigation levels and organic compost on okra plants (Abelmoschus esculentus 1.) grown in sandy calcareous soil. Agric Biol J N Am 1(3):225-231

Haggar J, Barrios M, Bolanos M, Merlo M, Moraga P, Munguia R et al (2011) Coffee agroecosystem performance under full sun, shade, conventional and organic management regimes in Central America. Agrofor Syst 82(3):285-301

Hess T, Stephens W, Weatherhead K, Knox J, Kay M (1998) Management of irrigation for tea and coffee, International Centre for Plantation Studies, Cranfield University

Ibrahim A, El-Samad G (2009) Effect of different irrigation regimes and partial substitution of $\mathrm{N}$-mineral by organic manures on water use, growth and productivity of Pomegranate trees. Eur J Sci Res 38(2):199-218

Kilian B, Connie J, Pratt L, Villalobos A (2006) Is sustainable agriculture a viable strategy to improve farm income in Central America? A case study on coffee. J Bus Res 59:330-332

Kutywayo D, Chingwara V, Mahoya C, Chemura A, Masaka J (2010) The effect of different levels of irrigation water and nitrogen fertilizer on vegetative growth components and yield of coffee in Zimbabwe. MSU J Sci Tech 2(2):45-54

Lekasi J, Tanner J, Kimani S, Harris P (2001) Managing manure to sustain smallholder livelihoods in East African highlands: DFID/ NRSP/HYDRA

Logan WJC, Biscoe J (1987) Coffee handbook. Zimbabwe Coffee Growers Association, Harare

Mufwanzala N, Dikinya O (2010) Impact of poultry manure and its associated salinity on the growth and yield of spinach (Spinacia oleracea) and carrot (Daucus carota). Int J Agric Biol 12(4):489-494

Njoroge JM, Mwakha E, Kimenia JK (1990) Effect of planting hole sizes and farm yard manure rates on establishment of high density Arabica coffee. Kenya Coffee 55(640):775-787

Nyalemegbe K, Oteng J, Asuming-Brempong s (2009) Integrated organic-inorganic fertilizer management for rice production on the vertisols of the Accra Plains of Ghana. West Africa J App Ecol 16:23-33

Ponte S (2004) Standards and sustainability in the coffee sector: a global value chain approach. IISD/UNCTD, Manitoba

Reganold JP, Glover JD, Andrews PK, Hinman HR (2001) Sustainability of three apple production systems. Nature 410:926-930

Satyanarayana V, Prasad P, Murthy V, Boote K (2002) Influence of integrated use of farmyard manure, inorganic fertilizers on yield and yield components of irrigated lowland rice. J Plant Nutr 25(10):2081-2090

Stockdale E, Shepherd M, Fortune S, Cuttle S (2002) Soil fertility in organic farming systems-fundamentally different? Soil Use Manag 18:301-308

Thomson JG, Purves WD (1981) A guide to the soils of Zimbabwe. Zimb Agric Res Tech Handb 3:13-14

Tscharntke T, Clough Y, Bhagwat SA, Buchori D, Faust H, Hertel D et al (2011) Multifunctional shade-tree management in tropical agroforestry landscapes-a review. J Appl Ecol 48(3):619-629

Van der Vossen H (2005) A critical analysis of the agronomic and economic sustainability of organic coffee production. Exp Agric 41:449-473

Worku M, Astatkie T (2010) Dry matter partitioning and physiological response of Coffea arabica varieties to soil moisture deficit stress at the seedling stage in Southwest Ethiopia. Africa J Agric Res 5(15):2066-2072

Wrigley G (1988) Coffee. Longman Scientific and Technical, London

Zafar M, Abbasi MK, Khaliq A, Rehman Z (2011) Effect of combining organic materials with inorganic phosphorous sources on growth, yield, energy content and phosphorous uptake in maize at Azad Jammu and Kashmir, Pakistan. Arch App Res 3(2):199-212 